\title{
EFFECT OF VISUAL AND VESTIBULAR INFORMATION ON SPATIAL PERCEPTION ON GAIT
}

original paper

( ) University School of Physical Education in Wroclaw

DOI: https://doi.org/10.5114/hm.2018.74058

\section{BRUNO SECCO FAQUIN ${ }^{1}$, CRISTIANE REGINA COELHO CANDIDO ${ }^{1}$, LUIS MOCHIZUKI ${ }^{2}$, VICTOR HUGO ALVES OKAZAKI ${ }^{1}$}

${ }^{1}$ Londrina State University, Londrina, Brazil

${ }^{2}$ Universidade de São Paulo, Sao Paulo, Brazil

\begin{abstract}
Purpose. Walking demands controlling body segments based on sensory information. Experimental manipulation of sensory information provides insight about how it interacts in situations of occlusion or perturbation of such information. This study examined the effect of manipulation of visual and vestibular information on spatial perception during gait.

Methods. Thirty-two participants aged between 19-34 years old walked straight ahead for 7 meters to reach the center point of the pathway. The authors measured the number of steps, movement time, and absolute error (deviation from the center of pathway end). They analyzed six experimental conditions: without spin with vision, without spin with visual occlusion, without spin with visual perturbation, with spin and vision, with spin and visual occlusion, and with spin and visual perturbation. Friedman's ANOVA test was used to compare the experimental conditions with a significance of $5 \%(p<0.05)$. Results. Occlusion and perturbation of visual information, and the perturbation of vestibular information, both affected the spatial orientation. The more sources of information that were occluded and/or perturbed; the greater was the decline of spatial perception. However, participants were able to perform the task of walking in all conditions with the manipulation of sensory information.
\end{abstract}

Conclusions. The authors suggest that there is a dynamic hierarchy in which the sensory sources can contribute in a particular way, due to the constraint imposed on the system.

Key words: postural balance, sensory deprivation, walking

\section{Introduction}

Gait is a complex motor skill that combines progression, postural control, and adaptation [1, 2]. Progression is moving towards the desired location. Postural control uses adjustments of body stabilization during locomotion; meanwhile, adaptation occurs according to individual's aims and environment demands [1]. Central nervous system (CNS), by anticipatory and reactive controls, manages context and task adaptations to ensure balance control. During anticipatory control, postural control counterbalances movement perturbation; then, reactive control is triggered by perturbation and is based on reflex responses [3]. For such strat- egies, the CNS integrates sensory and motorinformation [4-6].

Sensory information about the body position and movement [7, 8] for control of posture and movement comes from somatosensory, vestibular, and visual systems [4, 9]. Using this information, the CNS can anticipate applied forces onto the body and generates proper muscle action to maintain posture [10]. However, each sensory information has its own resolution and importance and one type of sensory information reliability may affect another [11]. Hierarchy of sensory information is not fixed and changes due to external demands and to minimize internal conflicts [12-14]. Thereby, dynamics of this hierarchy depends

Correspondence address: Victor Hugo Alves Okazaki, Universidade Estadual de Londrina, Centro de Educação Física e Desportos, Departamento de Fundamento 86.055-701 Londrina, Brazil, e-mail: vhaokazaki@gmail.com

Received: July 3, 2017

Accepted for publication: November 23, 2017

Citation: Faquin BS, Candido CRC, Mochizuki L, Okazaki VHA. Effect of visual and vestibular information on spatial perception on gait. Hum Mov. 2018;19(2):39-45; doi: https://doi.org/10.5114/hm.2018.74058. 
B.S. Faquin, C.R.C. Candido, L. Mochizuki, V.H.A. Okazaki, Gait spatial perception

on the task, available sensory information, and the aim of postural control $[5,15,16]$. The weight of sensory information can be rebalanced to overcome any system failure $[4,6,12,14]$. Despite the investigation of the sensory system's importance to reactive and proactive gait control [17-19], the effect of sensory manipulation on gait spatial orientation has not been properly investigated. A challenge for the motor behavior studies is to understand how the CNS integrates the sensory inputs within postural responses during gait [20].

The lack of visual information causes instability [4, 21-23] because the visual system provides information about the environment, objects, external events, body parts, and relative body position to the environment $[9,22]$. Thus, walking in a straight line may be trivial without any sensory information constraint. However, spatial orientation, which is essential for locomotion, is impaired by the lack of visual information [24]. Likewise, manipulation of vestibular system information could compromise the spatial orientation during locomotion.

Vestibular sensory information is important for locomotion [25]. Vestibular stimulation triggers postural responses balanced by adjustments in somatosensory and visual system sensibility, indicating sensory integration [26]. For example, body sway, induced by vestibular galvanic stimulation, decreases with visual information and increases standing on a foam surface or translation platform [27]. Such dependence among sensory systems changes according to how sensory information is controlled or altered within the task.

During locomotion tasks, vision builds an external reference frame. Vision and other sensory information are used to compare the actual and pre-programmed trajectories. Spatial perception during locomotion may change as a result of the sensory conflict, visual information constraint, and how the body moves in space [28]. However, the effect of manipulation of visual information and perturbation of vestibular information on spatial perception during locomotion is not fully understood.

Considering such issues, this study analyzed the effect of visual and vestibular information on spatial perception on gait. It was hypothesized that: $\mathrm{H}_{1}$ ) visual occlusion will impair locomotion more than other sensory manipulation; $\mathrm{H}_{2}$ ) the worst performance will happen with visual occlusion and vestibular perturbation. The manipulation of visual and vestibular system paradigm will help us to understand how the CNS reorganizes the contribution of each sensory system and how it adapts to inaccurate and conflicting inputs to maintain gait performance. In this way, this study supports the hierarchical, but dynamical, relevance of sensory systems for the performance of a motor task. Moreover, it provides insights about how individuals with deficits in sensory systems could adapt and show different strategies to walk, which would assist health professionals to rehabilitate these individuals.

\section{Material and methods}

\section{Sample Size Calculation}

To calculate the sample size, we use GPOWER software (v. 3.1) to simulate the needs for the two-tailed Friedman's ANOVA, considering 2 for variance ratio, $\alpha=0.05$; power $(1-\beta)=0,8$. This analysis has suggested at least 32 individuals for the sample size.

\section{Participants}

Participants were 32 adults between 19 and 34 years old (22.7 \pm 3.0 years old), 18 men $(75.25 \pm 7.98 \mathrm{~kg}$ weight, $1.74 \pm 0.06 \mathrm{~m}$ height, $24.84 \pm 2.52$ Body Mass Index) and 14 women $(61.91 \pm 8.20 \mathrm{~kg}$ weight, $1.61 \pm 0.08 \mathrm{~m}$ height; $23.83 \pm 2.61$ Body Mass Index).

\section{Locomotion task and spatial perception}

Participants walked straight ahead for $7 \mathrm{~m}$ to reach a target marked on the floor. The area for walking was delimited by markers placed on the floor on a semicircle with $7 \mathrm{~m}$ radius (Figure 1, panel A). These marks were used to measure the absolute error (AE), calculated as the distance between the target and where the participant crossed the semi-circle. Movement time (MT) and the number of steps (NS) performed until the participant crossed the semi-circle were measured.

\section{Manipulation of visual and vestibular information}

Vision was occluded with a black fabric blindfold. Visual information was perturbed with Chameleon's Eyes glasses (v.1.0) [29]. These glasses provided an ocular disparity projecting images of each eye with the angle of 45 degrees directed to the back of the participant, and each eye with a view of a different side (Figure 1, panel B and C). Vestibular system perturbation was performed by spinning the participant seated on a gyratory chair. Participants sat on a chair, feet on the chair seat, knees and hips flexed, and hands holding the chair support (Figure 1, panel D). Three 


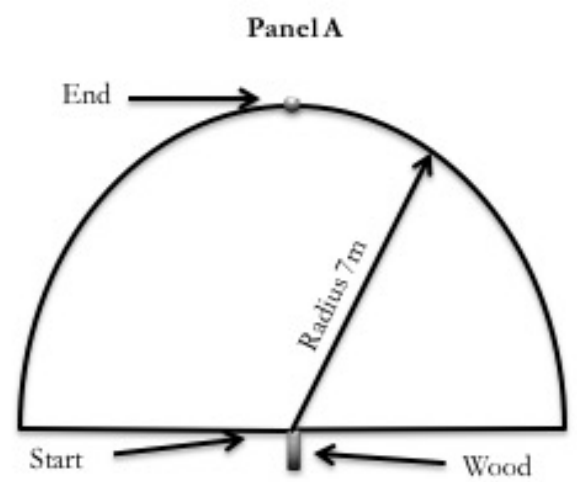

Panel B

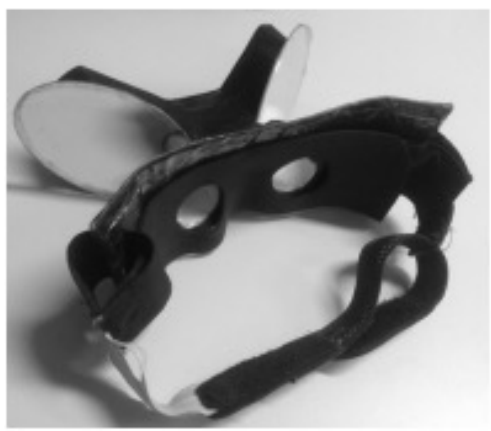

Panel D

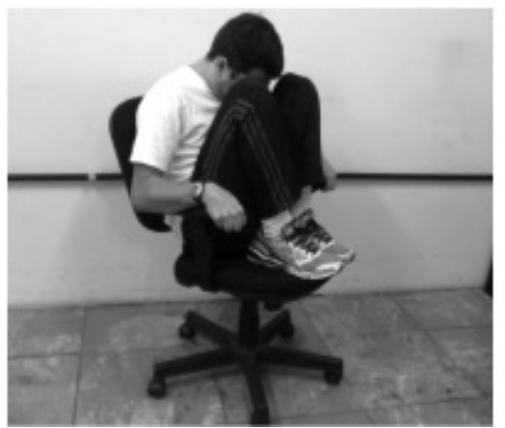

Panel C

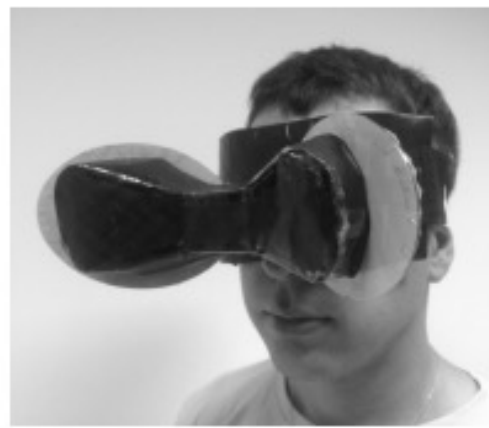

PanelE

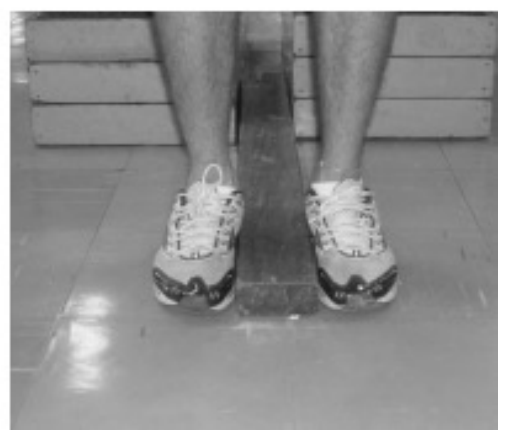

Panel A - Schematic representation of data collection site Panel B - Chameleon's Eyes

Panel C - disturbance of vestibular system with swivel chair Panel D - wood for standardization of the task start point

Figure 1. Schematic representation of the data collection place and equipment

persons rotated this gyratory chair and the participants to make them spin at $60 \mathrm{rpm}$ frequency for 20 seconds. Then, chair's rotation was stopped, the participant stood up while one evaluator held participant's hands to guide him/her to where the task would start. This spot was a round piece of wood $(20 \mathrm{~cm}$ width, $20 \mathrm{~cm}$ height, and $50 \mathrm{~cm}$ long) fixed on the floor and each participant held it with the internal side of the foot (Figure 1, panel E). This reference allowed the participants to begin the task from the same start position each time.

\section{Procedures}

Participants listened to the instructions about the task. Each participant performed the control condition (no rotation and with visual information) one time. For all conditions, participants walked with their usual gait pattern used in daily life activities. For the "with rotation" or "visual occlusion" conditions, two evaluators were close to the participant for safety. None of the participants fell during trials, they performed the task and its conditions successfully. 
Participants walked under six sensory information conditions: 1) control condition: non-rotation and with vision (NR-V); 2) non-rotation and non-vision (NR-NV); 3) non-rotation and perturbed vision (NR-PV); 4) with rotation and vision (R-V); 5) with rotation and nonvision (R-NV); and, 6) with rotation and perturbed vision (R-PV). To remove visual information, participants were blindfolded. To perturb vision, participants wore Chameleon's eyes glasses. For all participants, the control condition was the first task. The sequence of other conditions was random.

\section{Study Variables}

Dependent variables were: accuracy (absolute error, AE), motion (movement time, MT; and number of steps, NS) and performance index. Calculation of this index accounted all other dependent variables to provide a global reference of performance. Relative $\mathrm{AE}(\mathrm{AE} \%$, Equation 1) is performance in relation to task's greatest error ever $(11 \mathrm{~m})$. Relative motion variables (\%NS and \%MT, Equations 2 and 3, respectively) were normalized by control condition.

$A E \%=\frac{A E}{11}$

Equation 1

$N S \%=\frac{N S_{\text {condition }}}{N S_{N R-V}}$

Equation 2

$T M \%=\frac{T M_{\text {condition }}}{N R-V}$

Equation 3

After normalization, $\mathrm{AE}$ was the mean of those variables (Equation 4).

$P I=\frac{A E \%+M T \%+N S \%}{\mathbf{3}}$

Equation 4

\section{Statistical analysis}

Results were not normally distributed (ShapiroWilk test, $p<0.05)$. Data was described by median, $1^{\circ}$ and $3^{\circ}$ quartiles. Friedman's ANOVA was used to compare data. If necessary, Wilcoxon test was applied for paired comparisons. All analysis was performed in Statistica Software (v.6.0). Level of significance was set at $5 \%(p<0.05)$.

\section{Ethical approval}

The research related to human use has been complied with all the relevant national regulations and institutional policies, has followed the tenets of the Declaration of Helsinki, and has been approved by the authors' institutional review board or an equivalent committee.

Procedures of this study were approved by the university local Ethical Committee ( ${ }^{\circ}$ 387.130; CAAE $\mathrm{n}^{\mathrm{o}}$ 19884613.8.0000.5231).

\section{Informed consent}

Informed consent has been obtained from all individuals included in this study.

\section{Results}

Figure 2 presents AE for all conditions. Condition affected $\mathrm{AE}\left(X_{32,5}^{2}=116.5 ; p<0.001\right)$. AE was the lowest for NR-V condition $(p<0.001)$; AE was the lower for NR-NV than R-NV ( $p<0.001)$; AE was the lower for NR-PV than R-PV ( $p<0.001)$; AE was the lower for R-V than R-NV and R-PV $(p<0.001)$.

Figure 3 shows MT for all conditions. Condition affected MT $\left(X_{32,5}^{2}=62.7 ; p<0.001\right)$. MT was shorter for $\mathrm{R}-\mathrm{V}$ than NR-V $(p=0.02)$; MT was shorter for NR-V than NR-NV, NR-PV, R-NV, and R-PV ( $p=0.02)$; MT was shorter for NR-NV than NR-NV and NR-PV ( $p=$ 0.02); and, MT was shorter for R-V than R-NV and R-PV $(p<0.001)$.

Figure 4 presents NS for all conditions. Condition affected NS $\left(X_{32 ; 5}^{2}=72.3 ; p<0.001\right)$. NS was lower for NR-PV than NR-V $(p<0.001)$; NS was lower for NR-V than NR-NV, R-V, R-NV, R-PV ( $p=0.02)$; NS was lower for NG-NV than R-NV $(p<0.001)$; and NS was lower for R-V than R-NV and R-PV ( $p<0.001)$.

Figure 5 presents PI for all conditions. Condition affected PI $\left(X_{32,5}^{2}=112 ; p<0.001\right)$. Best PI was observed for NR-V $(p<0.01)$. PI was higher for NR-NV than R-NV and R-PV ( $p<0.01)$; NR-PV was higher than R-NV and R-PV ( $p<0.001)$; and R-V was higher than R-NV and R-PV $(p<0.001)$.

\section{Discussion}

Visual occlusion and perturbation of visual information disturbed the spatial perception during walking. Occlusion and perturbation increased absolute error, the number of steps, and movement time in comparison to the control condition. Larger absolute error reflects the worst trajectory prediction (spatial perception). Such worst prediction to walk straight ahead without proper visual feedback led to more steps and movement time. When participants used a reference to correct their trajectory, they rumbled and increased 


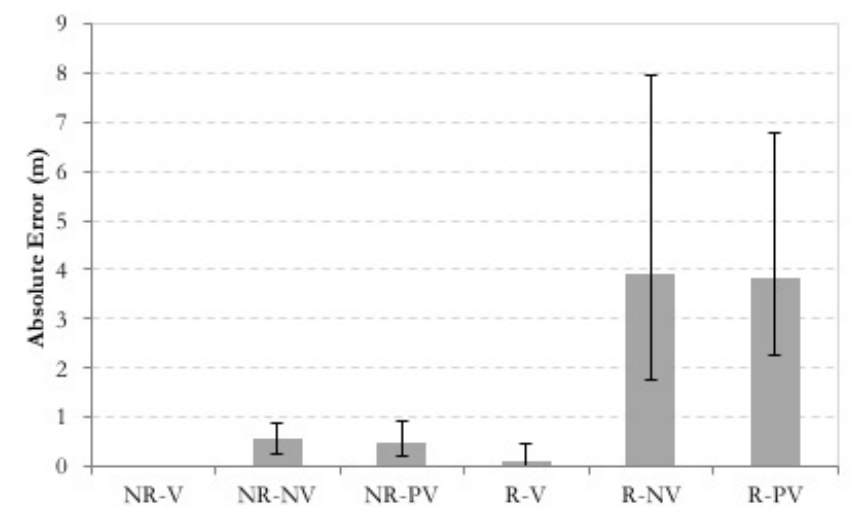

Different $(p<0.05)$ when compared to ${ }^{a} N R-V$, ${ }^{b} N R-N V,{ }^{c} N R-P V,{ }^{d} R-V,{ }^{e} R-N V$ and ${ }^{\mathrm{f}} \mathrm{R}-\mathrm{PV}$.

Figure 2. Median and $1^{\text {st }}$ and $3^{\text {rd }}$ quartiles of the Absolute Error (AE), as a function of the analyzed experimental conditions

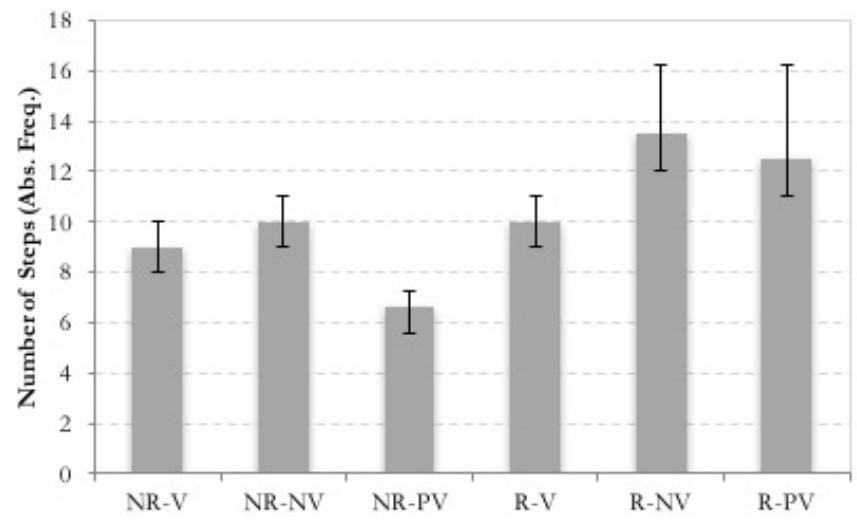

Different $(p<0.05)$ when compared to ${ }^{a} N R-V,{ }^{b} N R-N V,{ }^{c} N R-P V,{ }^{d} R-V,{ }^{e} R-N V$ and ${ }^{\mathrm{f}} \mathrm{R}-\mathrm{PV}$.

Figure 4. Median and $1^{\text {st }}$ and $3^{\text {rd }}$ quartiles of the Number of Steps (NS), as a function of the experimental conditions

movement time; therefore, their trajectories were even more irregular. These results reinforce that vision offers exteroceptive and proprioceptive information [9, 22]. Vision works as an integral component of the system that controls balance and may not be turned off voluntarily, except when the eyes are closed [22].

Visual information is important for spatial orientation. Blindfolded, our participants presented larger absolute errors and walked slowly. Optical flux helps to determine the gait velocity [30,31], because of more optical flux, higher cadence, and step length. Thereby, in addition to its basic function, vision is fundamental to late stabilization of postural corrections and to plan anticipatory actions.

Visual perturbation increased movement time. Such visual information conflicted with other sensory information available during gait, probably demanding more information processing, slowing other ongoing

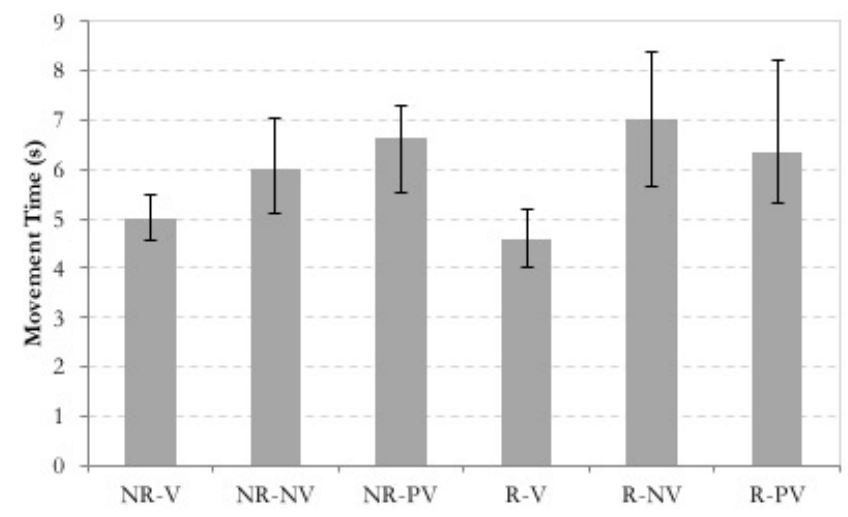

Legend: Different $(p<0.05)$ when compared to ${ }^{a} N R-V$, ${ }^{b} N R-N V,{ }^{c} N R-P V$, ${ }^{\mathrm{d}} \mathrm{R}-\mathrm{V},{ }^{\mathrm{e}} \mathrm{R}-\mathrm{NV}$ and ${ }^{\mathrm{f}} \mathrm{R}-\mathrm{PV}$.

Figure 3. Median and $1^{\text {st }}$ and $3^{\text {rd }}$ quartiles of the Movement Time (MT), as a function of the experimental conditions analyzed

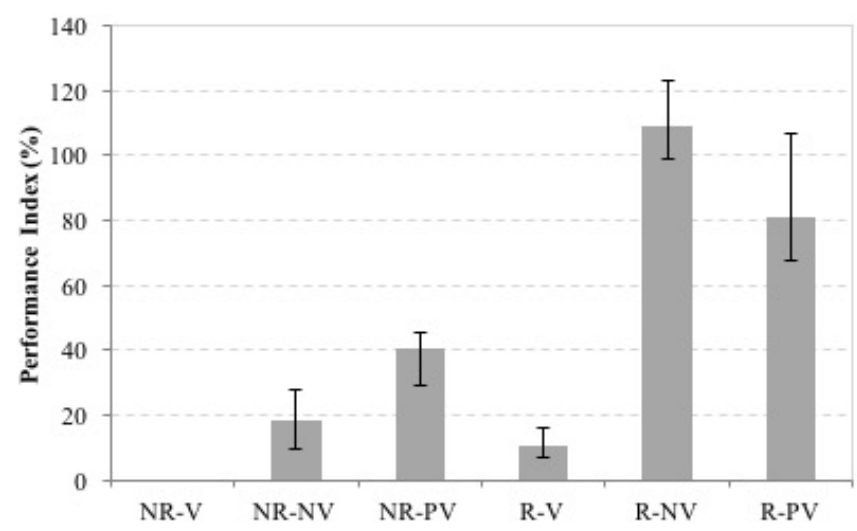

Different $(p<0.05)$ when compared to a NR-V, ${ }^{b} N R-N V,{ }^{c} N R-P V,{ }^{d} R-V,{ }^{e} R-N V$ and ${ }^{\mathrm{f}} \mathrm{R}-\mathrm{PV}$.

Figure 5. Performance Index (PI) as a function of experimental conditions

processes and turning performance worst [32]. More cognitive processes might have demanded more time to compare virtual and actual trajectories more frequently than usual. In fact, visual information is more important for complex tasks (35\%) compared to quite standing tasks (10\%) with no sensorial constraints [14].

Space orientation was worse with vestibular perturbation. Although, the task was completed faster; head rotation increased error and the number of steps required. Head rotation conflicts head position information and it adds bias to whole body positioning, deviating walking trajectory according to the rotation direction. Consequently, participants used more steps to compensate such bias. More steps suggest the need for more tactile information about the actual trajectory; moreover, more steps suggest reassessing of sensory information to walk. Peruch et al. [25] showed that less vestibular information impaired control of com- 
plex tasks such as locomotion and swing in the sinusoidal platform. Similar vestibular stimulation with a variation in visual and somatosensory inputs brings different postural responses, indicating a strong sensorial integration [26, 33]. Therefore, vestibular system perturbation (rotation) with the vision occlusion or perturbation impaired spatial orientation.

Another strategy to overcome vestibular perturbation was to perform the task faster to avoid lateral deviation, such a "walking drunk" style. Participants noticed that slow walking increased deviation from the desired path. Walking faster with more steps decreases step length and increases tactile information. Such results show how important the vestibular system is for spatial perception during walking and how postural system performs to compensate changes in sensory information.

Visual information added to vestibular information during walking led to more dependency (50\%) compared to quiet standing (30\%) [14]. Postural sway with vestibular galvanic stimulation increases, but less if combined with visual information and moreover an unstable surface (foam or moving platform) [27]. Thus, the hypothesis "manipulation of both sensory sources will result in worse performance for locomotion" was confirmed. But, the hypothesis "visual occlusion will prejudice locomotion performance more than the other sensorial manipulation" was refuted. Both, visual and vestibular manipulation provided very similar impairments to space orientation on locomotion. The more sensory sources were perturbed/occluded, the more space perception and orientation will be impaired.

Each kind of sensory information has its own resolution and importance, and the reliability of a sensory information affects another [11]. The dominance of a sensory system over the others is how the central nervous system dumps information conflicts [34]. This dominance is dynamic and depends on the task, availability of sensory information, and the aim of postural control $[4,14,15]$. Control as a dynamic and flexible system explains the proficiency to walk even with occlusion, visual or vestibular perturbation. However, these results should be interpreted carefully because manipulation of the somatosensory system was not contemplated. Although the generalization of our conclusions is constrained by characteristics of the participants, these results may help health professionals with the reintegration and rehabilitation of individuals with permanent or temporary sensory deficits.

\section{Conclusions}

Occlusion and/or perturbation of sensory sources impaired walking performance. This impairment was worse when both the vision and vestibular systems were perturbed. However, even under such perturbations, young adults completed the task. Motor control is flexible and dynamic to use sensory inputs to overcome imposed constraints. Perturbation of sensory information (visual and vestibular) induced movement adaptations to increase somatosensory information to assist task performance. More studies are suggested to analyze the manipulation of visual and vestibular information, simultaneously with somatosensory information (i.e., feet's mechanoreceptors).

\section{Acknowledgements}

We thank MEC/SESu for the scholarship of Tutor from the Tutorial Educational Program (PET) provided by the last author.

\section{Disclosure statement}

No author has any financial interest or received any financial benefit from this research.

\section{Conflict of interest}

We declare there is no conflict of interest.

\section{References}

1. Patla AE. Understanding the control of human locomotion: a prologue. Advances in Psychology. 1991;78:3-17; doi: 10.1016/S0166-4115(08)60735-9.

2. Das P, McCollum G. Invariant structure in locomotion. Neuroscience. 1988;25(3):1023-1034; doi: 10.1016/ 0306-4522(88)90055-3.

3. Horak FB, Nashner LM, Diener HC. Postural strategies associated with somatosensory and vestibular loss. Exp Brain Res. 1990;82(1):167-177; doi: 10.1007/BF00 230848.

4. Candido CRC, Faquin BS, Guidotti FJ, Porto AB, Okazaki VHA. Effect of visual occlusion on dynamic balance on installable platform. FIEP Bulletin On-line. 2012;82(2):347-350.

5. Castelani RA, Oliveira TFD, Faquin BS, Dascal JB, Marques I, Okazaki VHA. Analysis of dynamic balance in practitioners of classical ballet, of ballroom and nonpractitioners of dance [Análise do equilíbrio dinâmico em praticantes de balé clássico, de dança de salão e de não praticantes de dança, in Portuguese]. Rev Educ Fís UEM. 2014;25(4):597-607; doi: 10.4025/reveducfis.v25i4.22951.

6. Oliveira TFD, Vieira JLL, Santos A, Okazaki VHA. Dynamic balance in teenagers with Down Syndrome and teenagers with typical development [Equilíbrio dinâmi- 
co em adolescentes com Síndrome de Down e adolescentes com desenvolvimento típico, in Portuguese]. Motriz. 2013;19(2):378-390; doi: 10.1590/S1980-657420130 00200015.

7. Gurfinkel VS, Levick YS. Perceptual and automatic aspects of the postural body scheme. In: Paillard J. editor. Brain and space. New York: Oxford University Press; 1991. p. 147-162.

8. Mochizuki L, Amadio AC. Sensory information for postural control [As informações sensoriais para o controle postural, in Portuguese]. Fisioter Mov. 2006;19(2):11-18.

9. Duarte M. Stabilometric analysis of quasi-static human upright posture [Análise estabilográfica da postura ereta humana quasi-estática, in Portuguese]. Doctoral thesis. University of São Paulo, 2000.

10. Horak FB, Macpherson JM. Postural orientation and equilibrium. In: Shepard J, Rowell L, editors. Hand-book of physiology. Exercise: regulation and integration of multiple systems. New York: Oxford University; 1996. p. 255-292.

11. Lackner JR, Dizio P. Vestibular, proprioceptive, and haptic contributions to spatial orientation. Annu Rev Psychol. 2005;56(1):115-147; doi: 10.1146/annurev.psych.55. 090902.142023.

12. Cenciarini M, Peterka RJ. Stimulus-dependent changes in the vestibular contribution to human postural control. J Neurophysiol. 2006;95(5):2733-2750; doi: 10.1152/jn.00856.2004.

13. Oie KS, Kiemel T, Jeka JJ. Multisensory fusion: simultaneous re-weighting of vision and touch for the control of human posture. Cogn Brain Res. 2002;14(1):164176; doi: 10.1016/S0926-6410(02)00071-X.

14. Peterka RJ. Sensorimotor integration in human postural control. J Neurophysiol. 2002;88(3):1097-1118; doi: 10.1152/jn.2002.883.1097.

15. Candido CRC, Faquin BS, Okazaki VHA. Analysis of the constrained action hypothesis and the effect of the focus of attention in balance on unstable platform [Análise da hipótese de restrição da ação e do efeito do foco de atenção em tarefa de equilíbrio em plataforma instável, in Portuguese]. Rev Educ Fís UEM. 2012;23(4): 655-662; doi: 10.4025/reveducfis.v23i4.17036.

16. Meyer PF, Oddsson LIE, De Luca CJ. The role of plantar cutaneous sensation in unperturbed stance. Exp Brain Res. 2004;156(4):505-512; doi: 10.1007/s00221-0031804-y.

17. Nashner LM. Adaptation of human movement to altered environments. Trends in Neurosciences. 1982;5:358361; doi:10.1016/0166-2236(82)90204-1.

18. Peterka RJ, Black FO. Age-related changes in human posture control: sensory organization tests. Good Samaritan Hospital and Medical Center; Dept. of Neurootology.; Portland, OR, United States, 1989.

19. Woollacott MH, Shumway-Cook A, Nashner LM. Aging and posture control: changes in sensory organization and muscular coordination. Int J Aging Hum Dev. 1986; 23(2):97-114; doi: 10.2190/vxn3-n3rt-54jb-x16x.
20. Jeka JJ. Is Servo-Theory the Language of Human Postural Control? Ecological Psychology. 1995;7(4):321327; doi: 10.1207/s15326969eco0704_7.

21. Duarte M, Zatsiorsky VM. Effects of body lean and visual information on the equilibrium maintenance during stance. Exp Brain Res. 2002;146(1):60-69; doi: 10.1007/s00221-002-1154-1.

22. Lee DN, Lishman JR. Vision - the most efficient source of proprioceptive: information for balance control. Agressologie. 1977;18(A):83-94.

23. Rougier P. Visual feedback induces opposite effects on elementary centre of gravity and centre of pressure minus centre of gravity motions in undisturbed upright stance. Clin Biomech. 2003;18(4):341-349; doi: 10.1016/ S0268-033(03)00003-2.

24. Cosme RG, Albuquerque JE, Amadio AC, Mochizuki L. Spatial orientation in the locomotion of the elderly [Orientação espacial na locomoção de idosos, in Portuguese]. Brazilian Journal of Biomechanics (Impresso), 2010; 11:1-11.

25. Péruch P, Borel L, Gaunet F, Thinus-Blanc G, Magnan J, Lacour M. Spatial performance of unilateral vestibular defective patients in nonvisual versus visual navigation. J Vestib Res. 1999;9(1):37-47.

26. Bacsi AM, Colebatch JG. Evidence for reflex and perceptual vestibular contributions to postural control. Exp Brain Res. 2005;160(1):22-28; doi: 10.1007/S00221004-1982-2.

27. Horak FB, Hlavacka F. Somatosensory loss increases vestibulospinal sensitivity. J Neurophysiol. 2001;86(2): 575-585; doi: 10.1152/jn.2001.86.2.575.

28. Boyadjian A, Marin L, Danion F. Veering in human locomotion: the role of the effectors. Neurosci Lett. 1999; 265(1):21-24; doi:10.1016/s0304-3940(99)00198-6.

29. Okazaki VHA. Chameleon's Eyes glasses. 2010. Available from: [http://okazaki.webs.com].

30. Lackner JR, Dizio P. Visual stimulation affects the perception of voluntary leg movements during walking. Perception. 1988;17(1):71-80; doi: 10.1068/p170071.

31. Lackner JR, Dizio P. A Sensory-motor calibration processes constraining the perception of force and motion during locomotion. In: Wollacott MH, Horak FB, editors. Posture and Gait: Control Mechanisms. Eugene: University of Oregon; 1992.1:92-96.

32. Patla AE. A framework for understanding mobility problems in the elderly. In: Craik RL, Oatis CA, editors. Gait analysis: theory and application. St. Louis: Mosby-Year Book; 1995. p. 436-449.

33. Mergner T, Huber W, Becker W. Vestibular-neck interaction and transformation of sensory coordinates. J Vestib Res. 1997;7(4):347-367.

34. Massion J, Woollacott MH. Posture and equilibrium. In: Bronstein AM, Brandt T, Woollacott MH, Nutt JG, editors. Clinical Disorders of Balance, Posture and Gait. $2^{\text {nd }}$ ed. London: Arnold; 1996. p. 1-19. 